\title{
PREDICTION AND ENHANCEMENT OF THICKNESS REDUCTION IN MULTI-POINT FORMING PROCESS USING ANOVA ALGORITHM
}

Tahseen Fadhel Abaas

tfalani@yahoo.com
Karem MohsenYounis

karim_mohsen@yahoo.com
Khalida kadhim Mansor

kh_ak07@yahoo.com

Department of Production Engineering and Metallurgy / University of Technology

\begin{abstract}
Multipoint forming is an engineering concept which means that the working surface of the die and/or punch is made up of hemispherical ends of individual active elements (called pins), where each pin can be independently, vertically displaced using a geometrically reconfigurable die, precious production time is saved because several different products can be made without changing tools. The aim of this work is to present the effect of many parameters (blank Holder types, rubber thickness and forming speed) on the reduction of thickness for brass with $0.71 \mathrm{~mm}$ thickness. This research is concentrate on the development of predictive models to estimate the minimum deviation in thickness using analysis of variance (ANOVA), minimum thickness deviation has been modeled. In the development of this predictive model, blank holder, rubber thickness and forming speed have been considered as model parameters. Arithmetic the minimum thickness deviation used as response parameter to assess the thickness reduction of Multipoint forming parts. The data required has been generated, compared and evaluated to the proposed models that obtained from experiments. Taguchi algorithm is used to predict the effect of forming parameters on thickness reduction in forming process of Brass (65-35) based on orthogonal array of L9. The analysis of variance was used to find the best factors that effect on the thickness deviation, The result of this research is the contribution of blank holder types, rubber thickness and forming speed with respect to minimum thickness deviation is $(69.195$, 18.1 and 12.733$) \%$ respectively.
\end{abstract}

KEY WORDS: Multipoint forming process (MPF), Forming Parameters, Taguchi algorithm, Thickness deviation, and Analysis of variance (ANOVA).

$$
\begin{aligned}
& \text { تخمين وتحسين انخفاض السمك الحاصل في عملية التشكيل المتعدد التقاط } \\
& \text { باستخدام خوارزمية تحليل التباين }
\end{aligned}
$$

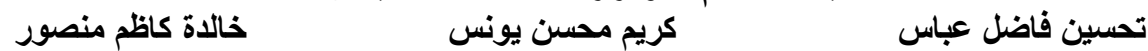

التشكيل المتعدد النقاط هو مفهوم هندسي الذي يعنى بتشكيل السطح باستخدام قالب علوي ونسي وسفلي متكون من عدد ذات ذات نهايات

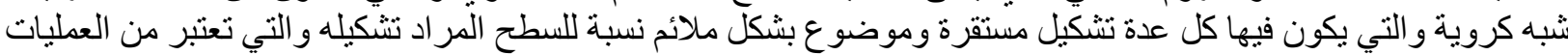

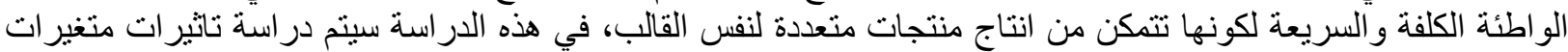

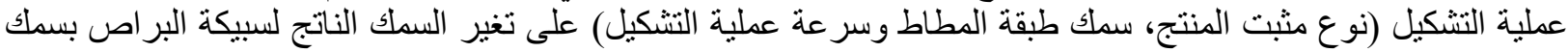

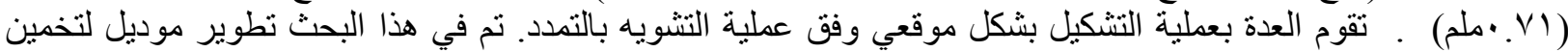

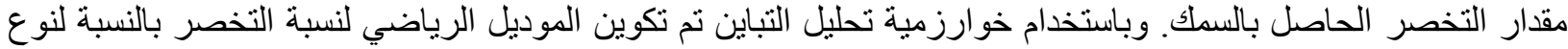

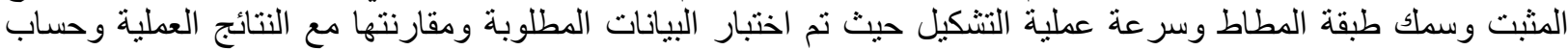

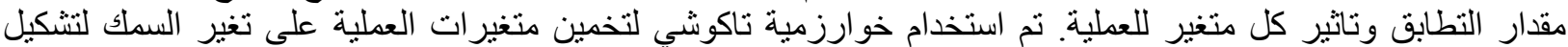

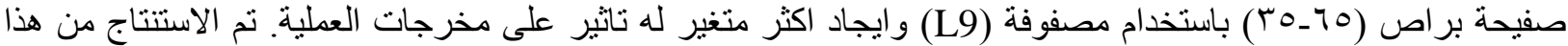

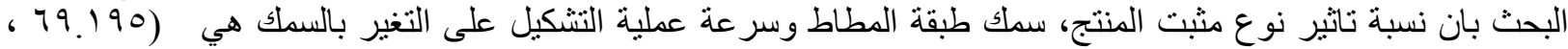

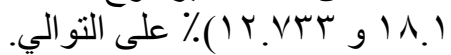

كلمات الاستدالة: عملية التشكيل المتعدد النقاط، عوامل عملية التشكيل، طريقة تاكوشي، الانحراف بالسمك، طريقة تحليل التباين (انوفا). 


\section{INTRODUCTION}

Multi-point forming (MPF) is a novel manufacturing technique for three-dimensional sheet metal. The discrete punches are composed of a pair of reconfigurable MPF dies and the shapes of the dies can be changed with requirement during the process of sheet forming [Zhong-Yi Cai et al -2002]. The effective method for manufacturing sheet metal product of 3D complex shapes is sheet metal forming process. This traditional process use a matched solid die set that forms a cavity into which the sheet is displaced. Sometimes, several sets may be needed to form a sheet metal parts. In this process, to produce different shaped parts different dies are required. The design and manufacturing of equipment such as punch and dies is a costly work and must rely on the experience of designers and workers. The idea of die forming of variable shape has always been attractive as a means of reducing die design costs.[Abdulkareem Jalil Kadhim et al -2014].The schematic of a multi-point forming process with a blank holder is shown in Figure (1). [Zhong-Yi Cai et al -2006]

\section{LITERATURE REVIEW}

A series of experiment have been carried out in design of experiments to investigate the effect of forming parameters such as blank Holder, thickness of polymer and forming speed on surface roughness. Q. Zhang and et al., (2007), studied the performance of an adjustable blank holder and a multi-pin die with pins in circular array. This die is acceptable to form the product with rotational shape. Also, presented the inverse displacement compensation by using a die shape optimization design method. Simulation and Experimental results from forming a spherical shell sector, with a diameter of $380 \mathrm{~mm}$ show this method is feasible and effective. the blank holder can reduce or eliminate dimples that show as the results also sometimes arise in the work-piece and the deformation of the interpolator during the forming process can induce a shape error in the formed work-piece. Ming Zhe Li and et al., (2007), improve dimensional accuracy of the formed part and investigated the compensate value of material springback. The system was developed to control the material flow using a DDF system with multi-point blank holder, thereby to prevent sheet parts from tearing and wrinkling. The DDF integrated system is described and the detailed forming procedures are explained in the work. Yajie Liu et al., (2016), designed an original rigid flexible blank holder $(\mathrm{FBH})$ device. Models of Finite element analysis $(\mathrm{FBH})$ are established without used of blank holder $(\mathrm{NBH})$; the simulation is applying with different BHF in spherical surface parts and then acquired the optimal BHF. The results indicate that FBH forming process can be release effectively wrinkling defects, thickness distribution is more reasonable, sheet metal flow is more uniform, and distribute uniformly and the stress and strain are minimum. A A Tolipov et al., (2017), investigated the effect of process variable such as the force of blank holder, elastic cushion thickness, radius of curvature and coefficient of friction on the performance of forming parts in a flexible multi-point process the research was carried out a multipoint forming process using a blank holder in order to study the effects of the, dimpling, wrinkling forming force and reduction of thickness and determine the optimum value of these variables. And by using finite element modeling to simulate the multipoint forming of hemispherical shapes. The effects of process variables on maximum deviation from thickness reduction, the target shape and wrinkling were estimate using the response surface methodology. Tahseen Fadhel Abaas et al., (2018), investigated the achievement of a multipoint die with tools in square matrix and suitable blank holder. Each pin in the punch holder can be a significant moved according to the die high and at different load that applied with spring with respect to spring stiffness. The results shows the reduction in setting time with respect to traditional single point incremental forming process that lead to $(90 \%)$. and also show during the forming process, the deformation of the interpolator formed work-piece can induce a shape error and the blank holder can eliminate or reduce dimples in 
the work-piece that sometimes arise. The aim of this work is to find the optimum value of some process variable that effect on thickness reduction and estimate the empirical equation that present the reduction value with respect to process variables.

\section{EXPERIMENTAL WORK \\ Material and process}

In this work, nine samples of brass $(\mathrm{Cu} \mathrm{Zn} \mathrm{65-35)}$ with thickness $0.71 \mathrm{~mm}$, were used to perform the experimental work and different dimension. The geometry of forming tool is shown in Figure (2). While the geometry of final product illustrated in Figure (3).

The experimental work was applied using oil lubricant on a C-tek three-axis (KM-80D), CNC milling machine equipped with a maximum rotational speed of $6000 \mathrm{rpm}$, feed rate of $10 \mathrm{~m} / \mathrm{min}$. CNC part programs for tool path was created to manufacturing the CAD model that used as the lower die. The experimental work of the workpiece for hem-spherical. The chemical composition and mechanical properties of this brass (65-35) is illustrated in Tables $(1 \& 2)$. For forming operation the tool used for performing is square tool steel $316(15 \times 15)$ $\mathrm{mm}$. three types of blank holder was used in this work with different size and shape that illustrated in Figure (4) while, Figures (5) presented the schematic of multi point forming die and the final nine products. By using a micrometers measuring device, the forming surface was measured after cut off samples, and the measurement procedures at three different positions are used to evaluate the thickness deviation of multipoint forming product as the output parameters and each values are recorded in $(\mu \mathrm{m})$.the micrometers measurement device illustrated in Figure (6).

\section{PROCEDURE OF EXPERIMENTS}

An important stage in response surface model generation using ANOVA is the planning of experiments. The factors which have a significant influence on Thickness reduction was identified by blank holder types, rubber thickness and forming speed in multi-point process. The powerful tool for improving productivity is Taguchi method has become during research and development in recent years so at low cost that can be produced good quality parts quickly. Uses a special design of orthogonal arrays with a small number of experiments Taguchi method is to study the entire parameter space. The methodology of Taguchi for three factors at three levels is applied of experiments. To define the nine trial conditions, the degrees of freedom required for the study is six and Taguchi's (L9) orthogonal array. The levels and process parameters are illustrated in Table (3). The average response and Replicated twice values for each of the nine trials or process designs are used in this work. Table (4) illustrated the process parameters and maximum reduction percentage, while Table (5) presented the testing results for nine product at twenty samples for each one.

\section{PREDICTION OF PROCESS PARAMETERS}

Using Taguchi's algorithm to predict the effect of each parameters on the response value and estimate the empirical equation contribute between each process parameter in second order that illustrated in equation (1) to optimize the present work, From the given data (blank holder (B), rubber thickness (R) and forming speed (S) with respect to Thickness deviation. Table (6) presents the final prediction value using Taguchi's algorithm, while Table (7) present the analysis of variance using ANOVA algorithm. 
Reduction $=12.993-3.053 \mathrm{~B}-1.543 \mathrm{R}+0.845 \mathrm{~S}+0.5615 \mathrm{~B}^{2}+0.1389 \mathrm{R}^{2}-$ $0.07916 \mathrm{~S}^{2}-0.0036 \mathrm{BR}-0.0222 \mathrm{BS}+0.0209 \mathrm{RS}$

And by using ANOVA algorithm to find the value of confidence of empirical equation that result from this work as the following:

Level of confidence $(\mathrm{F}$-value $)=95 \%=0.95$

Level of significance $(\mathrm{P}-\mathrm{value})=5 \%=0.05$

\section{1- P-value}

$\mathrm{P}<0.05 \rightarrow$ Significant

$\mathrm{P}>0.05 \rightarrow$ Non- Significant (neglected)

\section{2- Fisher value (F-value)}

F > FT ( from Table (7) ) Critical tabulated

$\mathrm{FT}=4.4513$

Percent of contribution $\%=\frac{\text { Adj } s s}{\text { Total Adj } s s} * 100 \%$

\section{Percent of contribution \%}

1. Blank holder $=69.195 \%$

2. Rubber thickness $=18.1 \%$

3. Speed of forming $=12.733 \%$

\section{RESULTS AND DISCUSSION}

The results of this work is the effect of various variables of forming parameters (blank holder (B), rubber thickness (R) and forming speed (S)) with respect to reduction percentage that that occurs on the forming parts of Brass $(\mathrm{Cu} \mathrm{Zn} \mathrm{65-35)}$ using multi-point forming process. The figures were result from the experimental work using ANOVA algorithm that illustrated in Figures (7, 8 and 9). The effects of two input parameters represents in each curve in otherwise the parameter was kept constant.

The effect of blank holder on the maximum reduction percentage at the different rubber thickness and forming speed were used. In this work, with respect to the range of forming parameters used, explain that at the highest values of forming speed and the second type of blank holder occurs maximum reduction of thickness, see Figures (7) and (10). While Figure (8) presents the variance of reduction value with respect to three process parameters. The final result is estimate the empirical model of each forming parameters with respect to thickness reduction percentage using Taguchi's algorithm and find the contribution of blank holder types, rubber thickness and forming speed with respect to minimum thickness deviation is (69.195, 18.1 and 12.733) \% respectively that presented in Figure (11).

\section{CONCLUSIONS}

The current research reviewed some important aspects related with surface quality on forming of materials with special emphasis in brass-alloy. Based on the results of the above research on surface quality in multi-point forming process using ANOVA algorithm, the following conclusions can be draw: 
1. The results of ANOVA Algorithm and the effectiveness experiments confirm that the developed empirical models for the output responses provide the predicted values and shows an excellent fit of these response factors that are close to the experimental values, at $(95) \%$ confidence level.

2. Low forming speed gave the low thickness reduction, because give them enough time for the metal to reorganize the atoms and thus reduce the strength of the metal resistance to the forming force, the effectiveness range up to $(12.733 \%)$.

3. Maximum rubber thickness takes the low thickness reduction because the forming force was distributed on wide forming area, the effectiveness range up to $(18.1 \%)$

4. The blank holder type (1) gave the low thickness reduction up to (69.195\%).

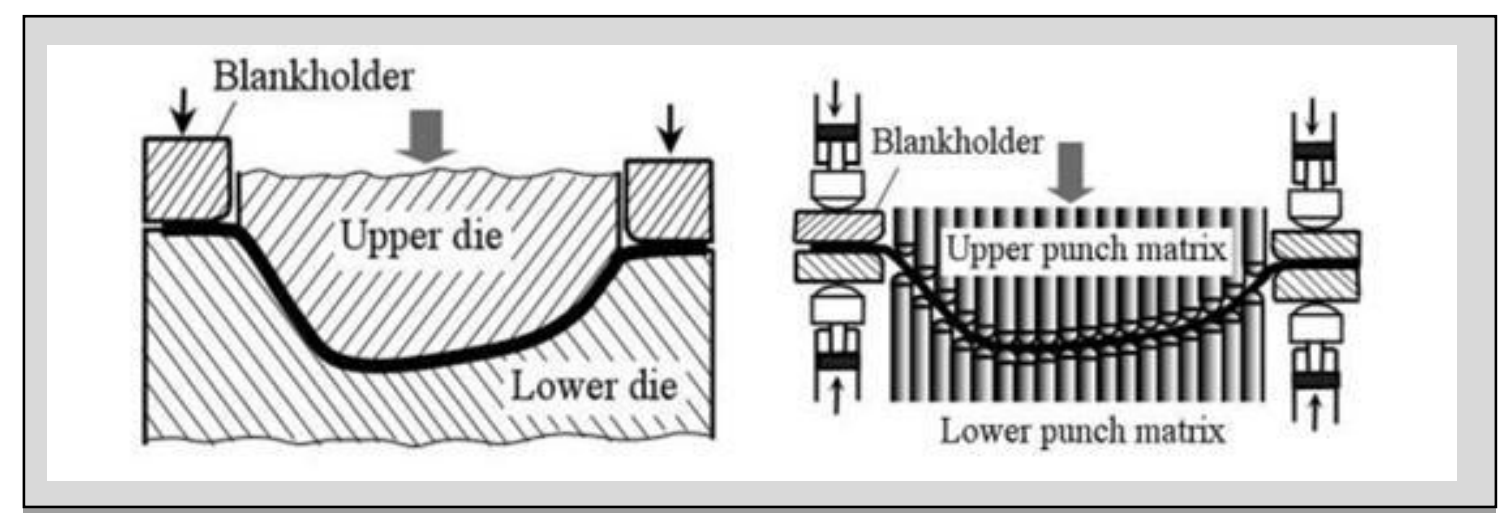

Figure (1) Fundamental of sheet metal forming: a) Conventional die Forming

(b) Flexible forming dies. [Zhong-Yi Cai et al -2006]

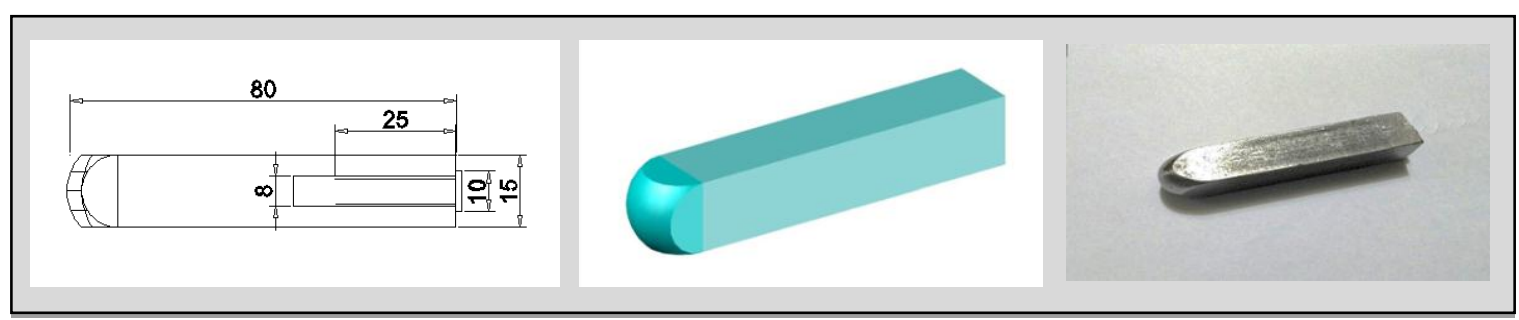

Figure (2) Geometry of forming tool 


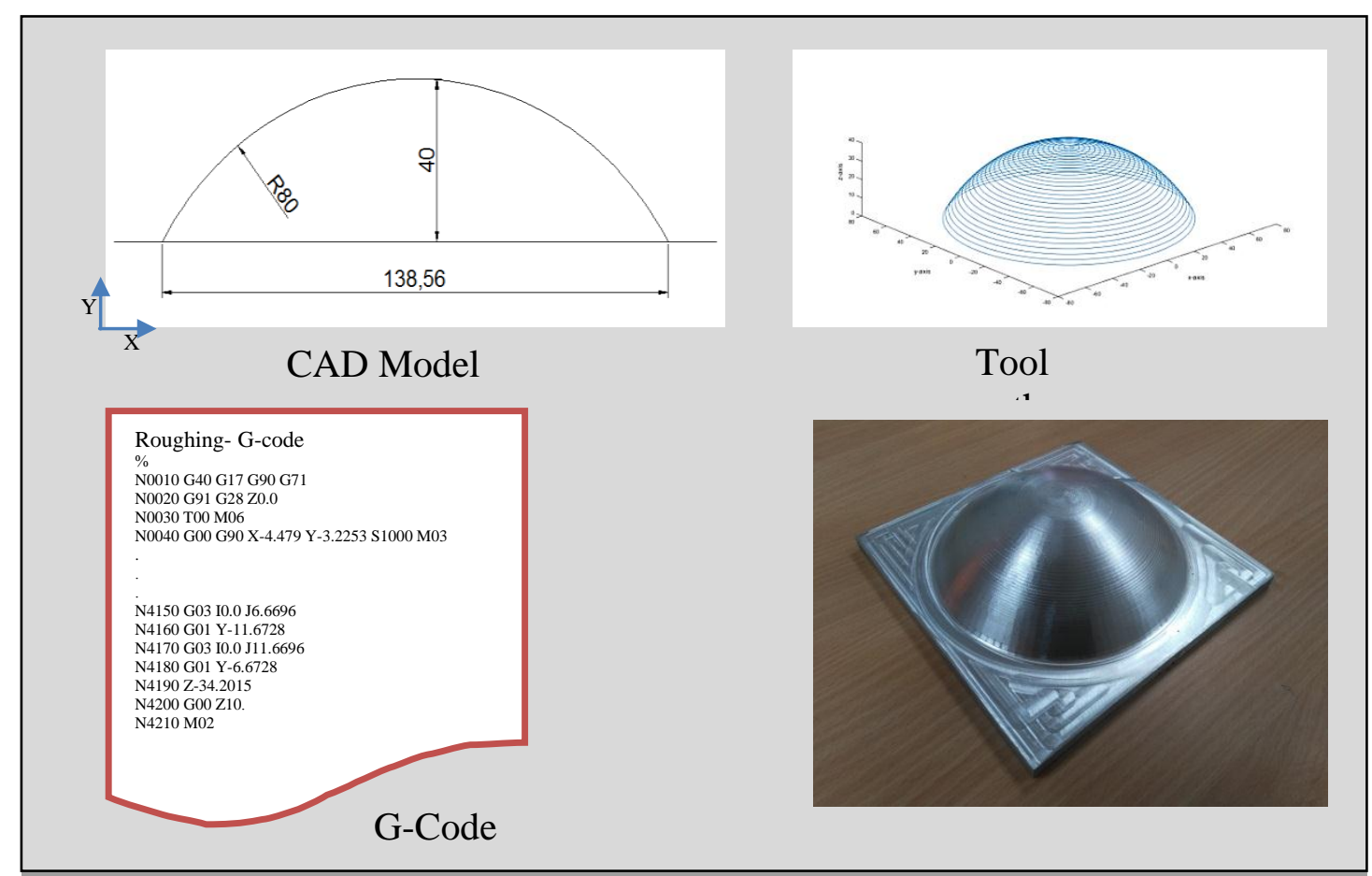

Figure (3) CAD-geometry of product and part program.

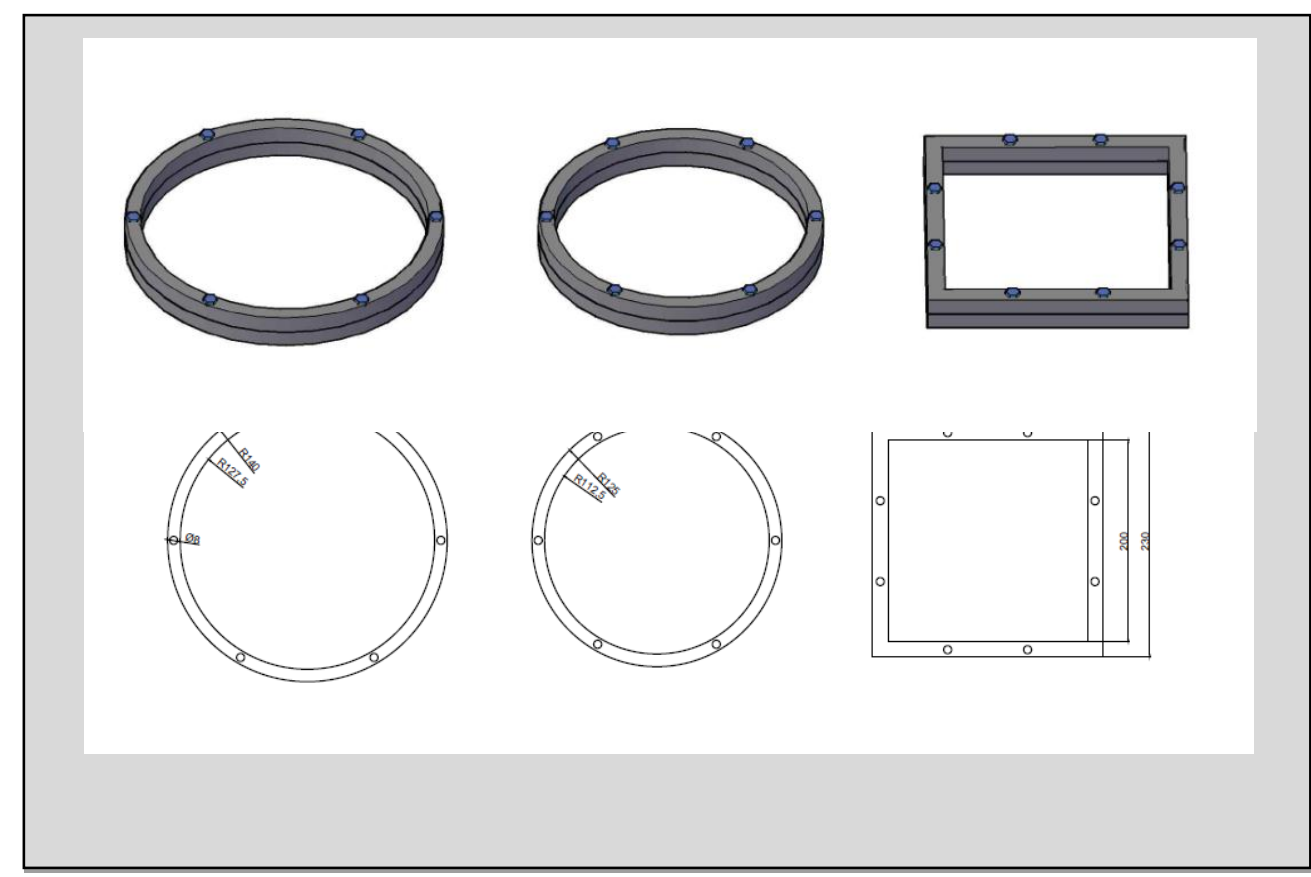

(1)

(2)

(3)

Figure (4) Types of blank holder that used in this work 


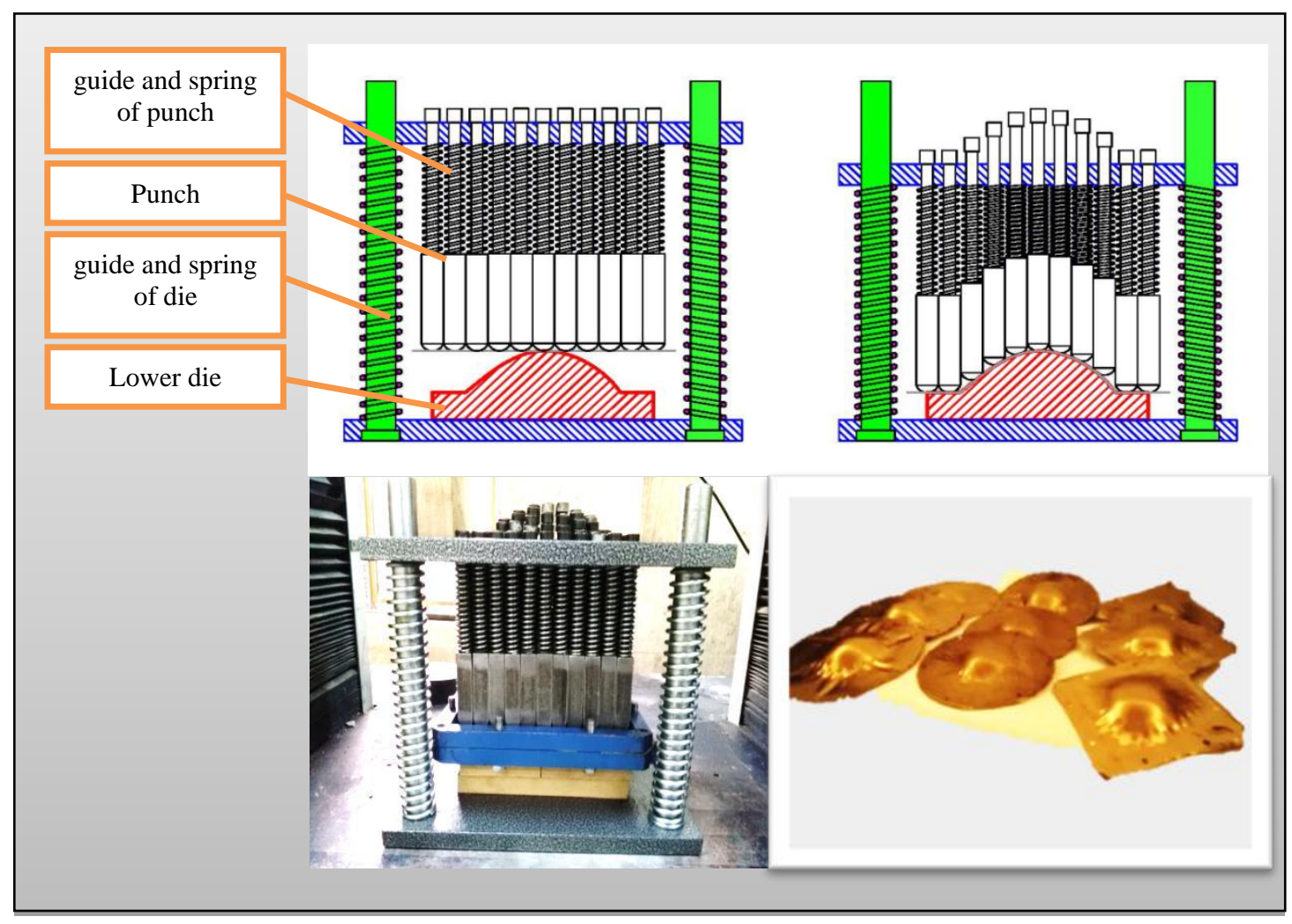

Figure (5) The experimental setup and nine-samples

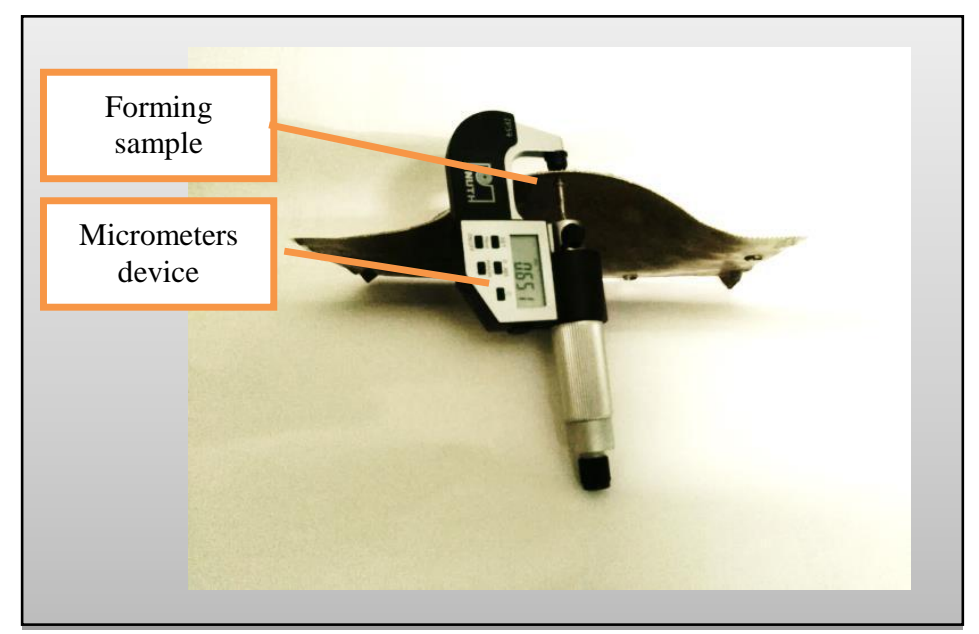

Figure (6) Micrometers measurement device 
Surface Plot of Reduction \& blank holder; rubber

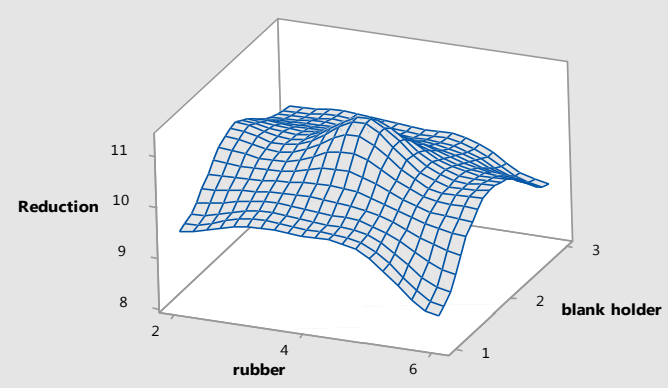

Surface Plot of Reduction \& blank holder; speed

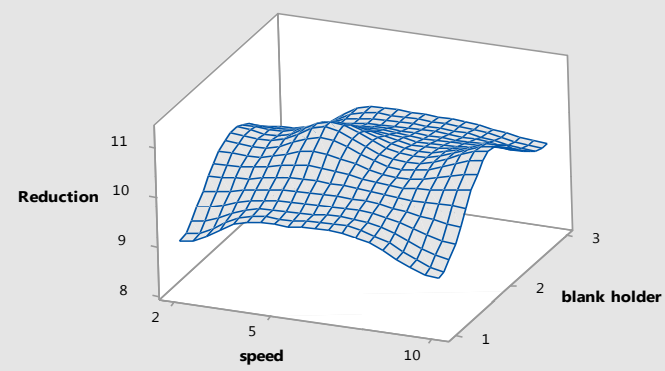

Surface Plot of Reduction \& rubber; speed

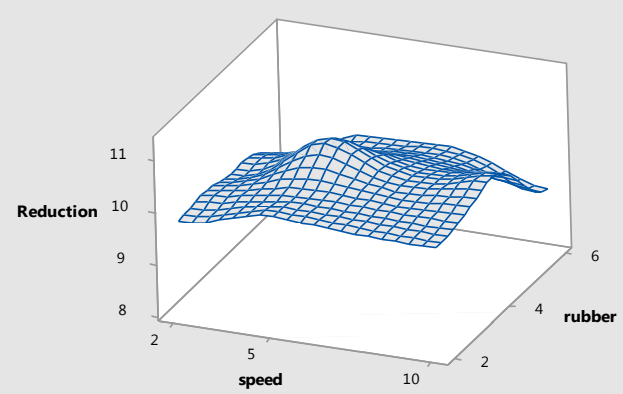

Figure (7) The relationship of reduction percentage (\%) with respect to process variables 


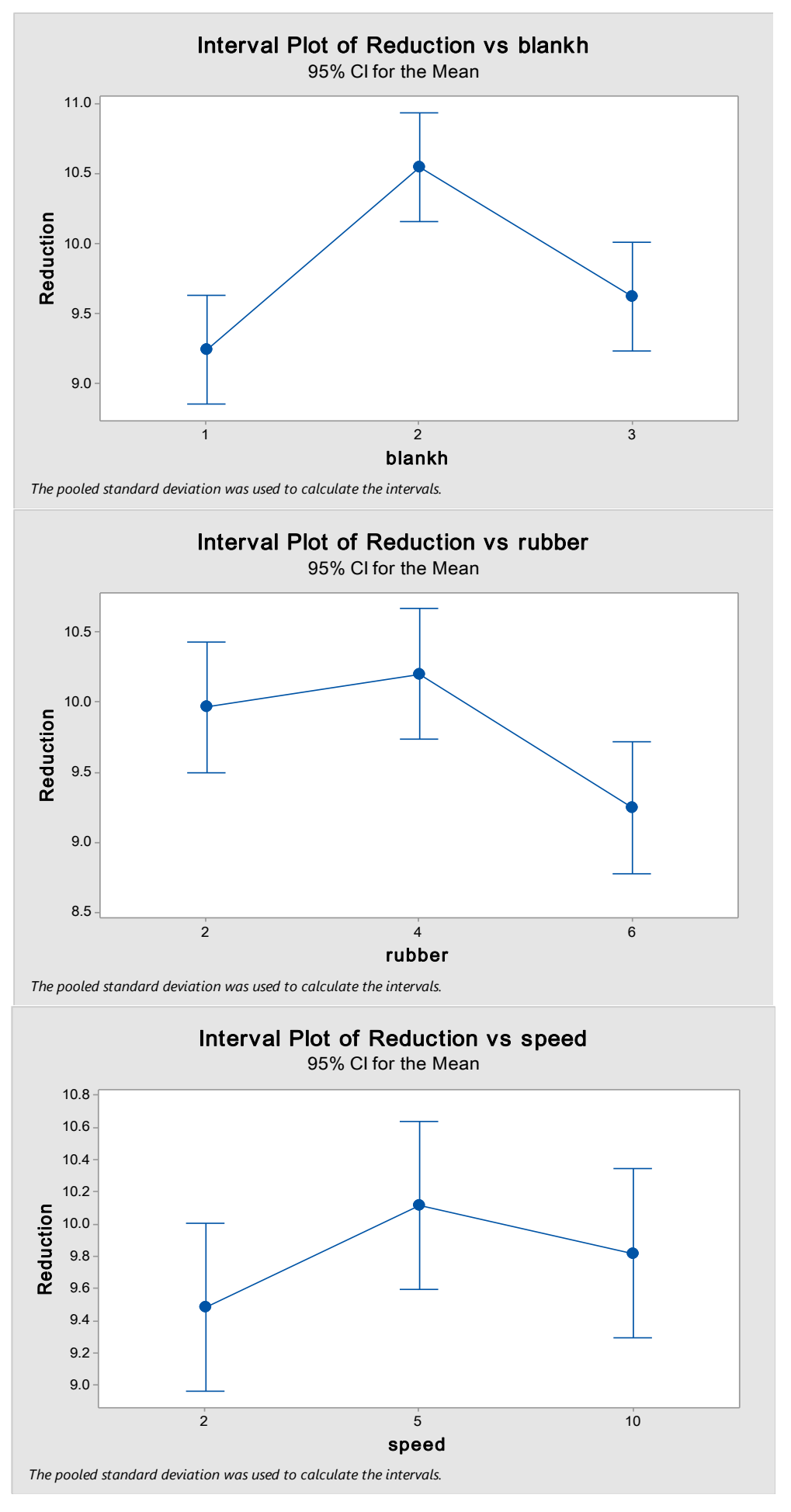

Figure (8) The relationship of mean effect with respect to process variables 


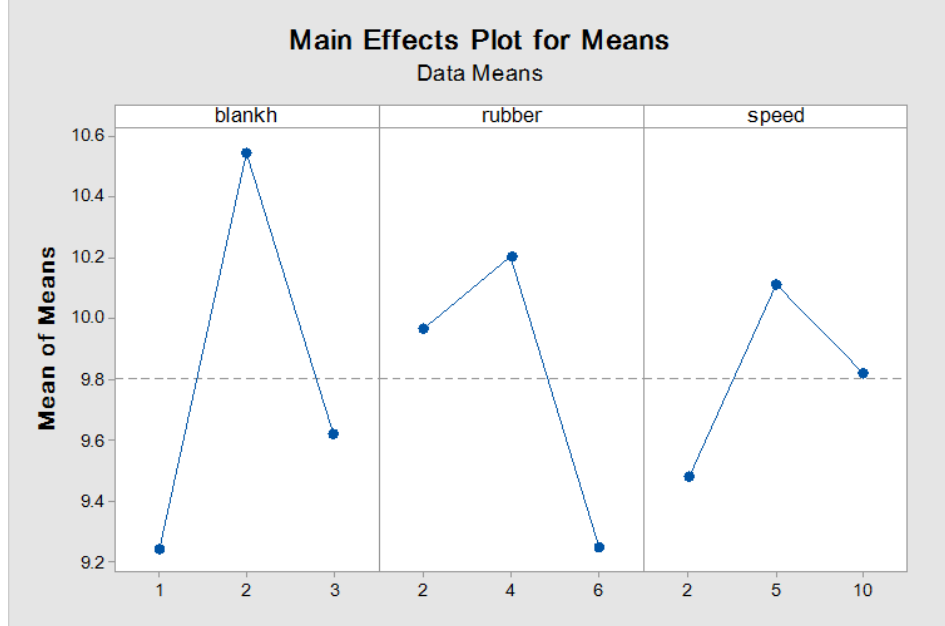

Figure (9) The relationship of response value with respect to process variables

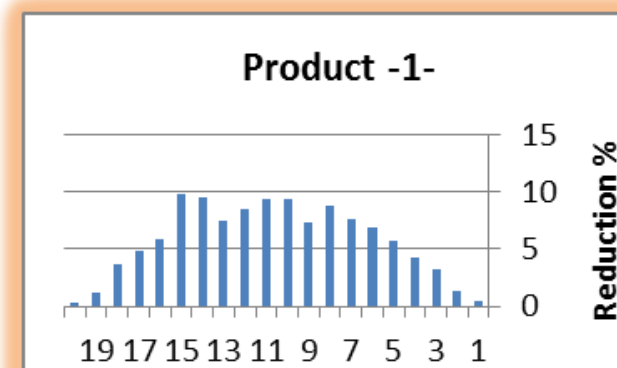

Sample No.

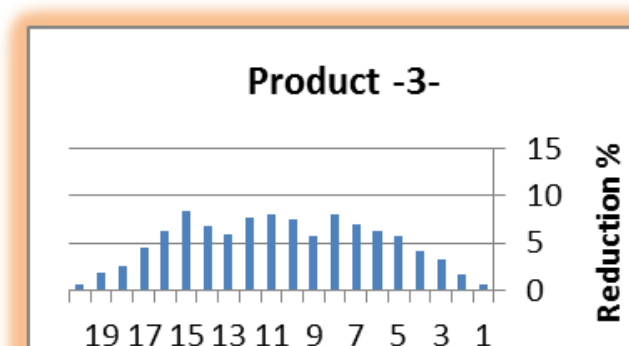

Sample No.

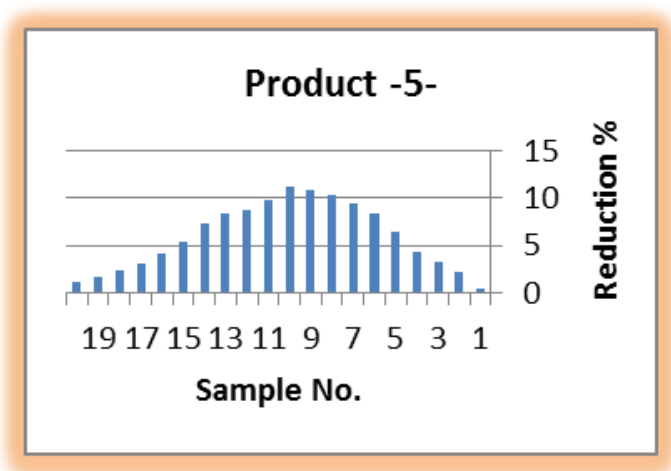

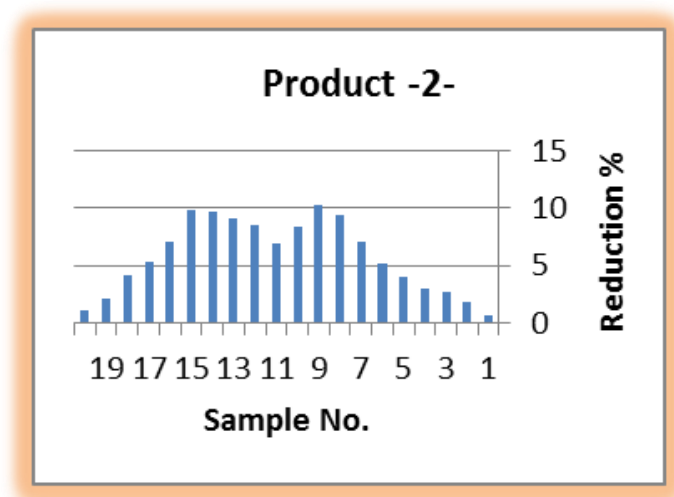

\section{Product -4-}

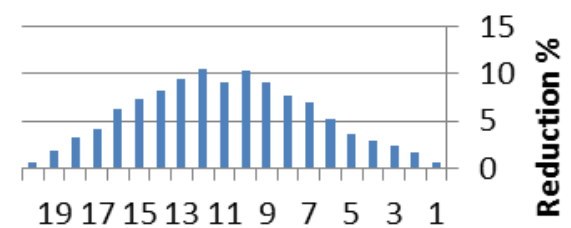

Sample No.

\section{Product -6-}

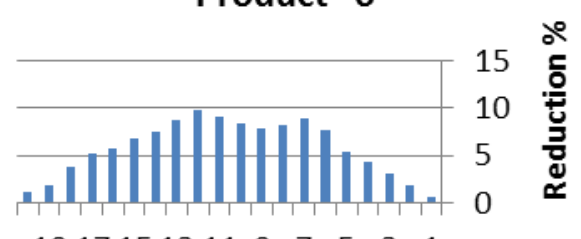

$19171513119745 \quad 3 \quad 1$

Sample No. 

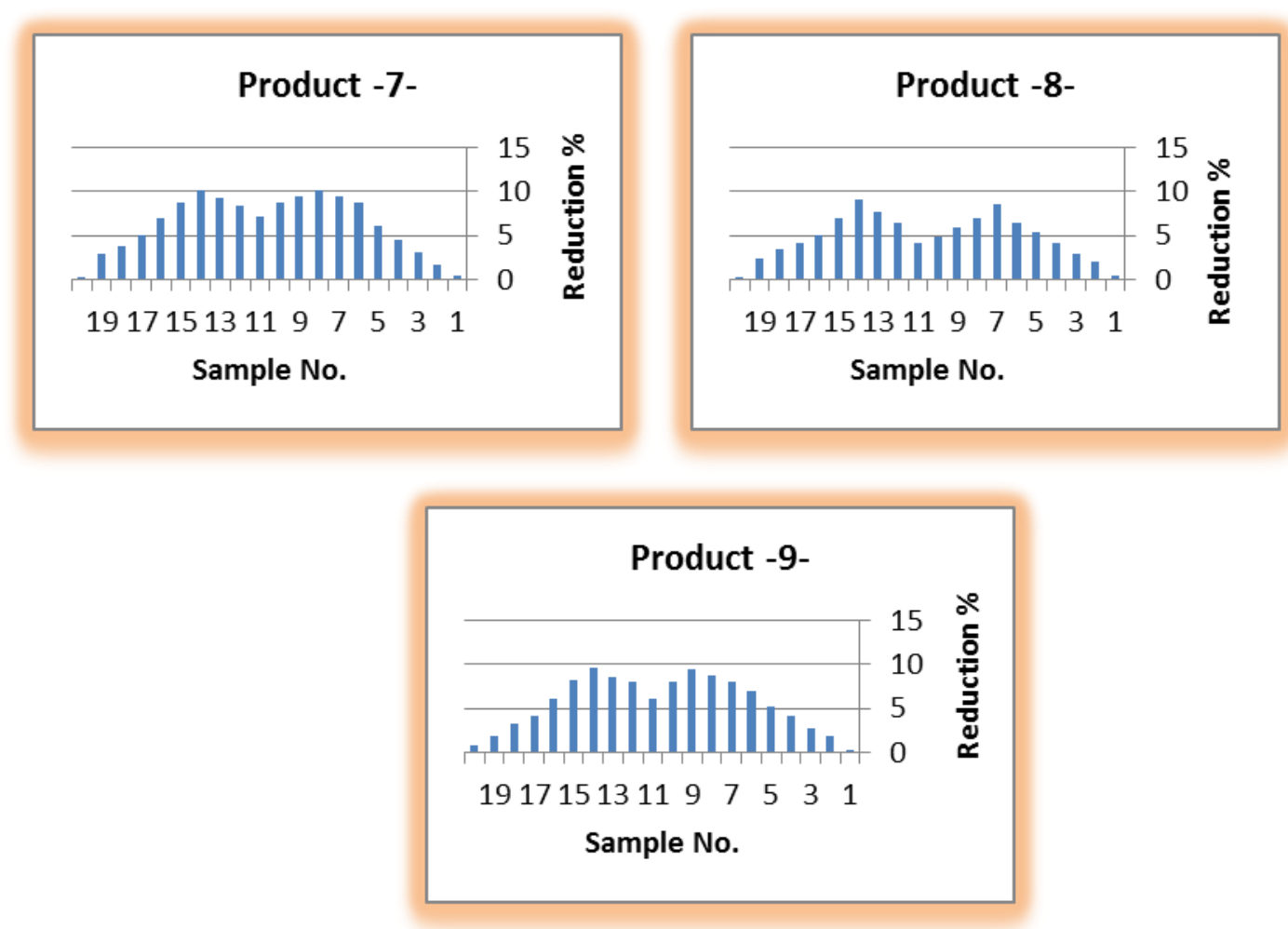

Figure (10) Thickness reduction percentage with respect to testing samples for each nine forming products

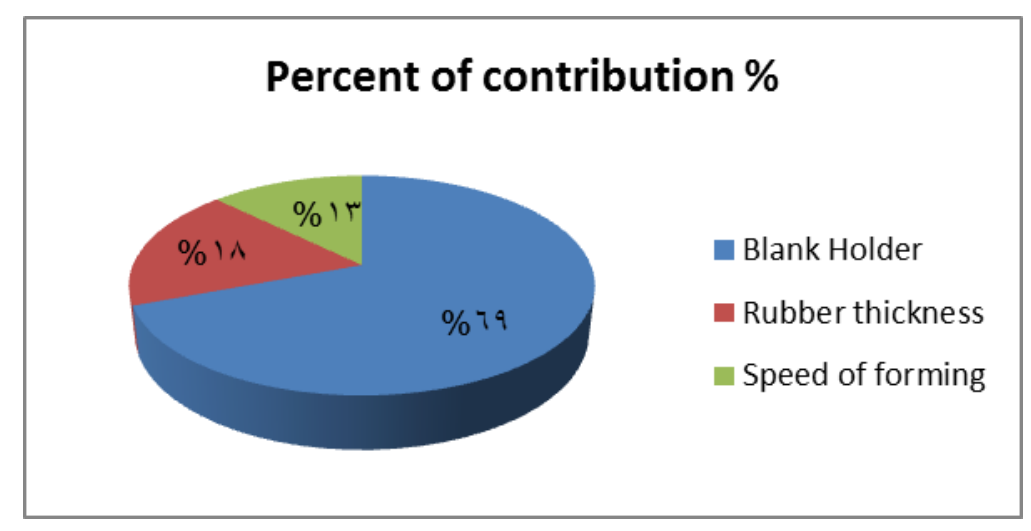

Figure (11) The contribution of process parameters that effect on thickness reduction.

Table (1) Chemical composition of Brass 65-35 sheet (Iso- Cu Zn 65-35 426/1).

\begin{tabular}{|c|c|c|c|c|c|c|c|c|c|c|c|}
\hline \multicolumn{2}{|c|}{ Material } & $\mathrm{Zn} \%$ & $\mathrm{~Pb} \%$ & $\mathrm{Sn} \%$ & $\mathrm{P} \%$ & $\mathrm{Mn} \%$ & $\mathrm{Fe} \%$ & $\mathrm{Ni} \%$ & $\mathrm{Si} \%$ & $\mathrm{Al} \%$ & $\mathrm{Cu} \%$ \\
\hline \multirow{2}{*}{ Brass } & Exp. & 35.23 & 0.007 & 0.001 & 0.007 & 0.000 & 0.021 & 0.001 & 0.001 & 0.002 & 64.7 \\
\cline { 2 - 12 } & Iso & 35.0 & 0.0 & 0.0 & 0.0 & 0.0 & 0.0 & 0.0 & 0.0 & 0.0 & 65.0 \\
\hline
\end{tabular}


Table (2) Mechanical properties for Brass 65-35 sheet (Iso- Cu Zn 65-35 426/1).

\begin{tabular}{|c|c|c|c|c|c|c|l|}
\hline \multicolumn{2}{|c|}{ Material } & $\begin{array}{c}\text { Tensile Strength } \\
\text { Mpa }\end{array}$ & $\begin{array}{c}\text { Modulus of } \\
\text { Elasticity Gpa }\end{array}$ & $\begin{array}{c}\text { Poissons } \\
\text { Ratio }\end{array}$ & $\begin{array}{c}\text { Elongation \% on } \\
50 \text { mm G.L. }\end{array}$ & $\begin{array}{c}\text { Vickers } \\
\text { Hardness VPN }\end{array}$ & \multicolumn{1}{|c|}{ Iso } \\
\hline \multirow{2}{*}{$\begin{array}{c}65 / 35 \\
\text { Brass 'O' }\end{array}$} & Exp. & 230 & 110 & 0.375 & 31.5 & $\leq 100$ & Cu Zn 35 \\
\cline { 2 - 7 } & Iso & 230 & 110 & 0.33 & 56 & $\leq 90$ & $426 / 1$ \\
\hline
\end{tabular}

Table (3) Multipoint levels and parameters

\begin{tabular}{l|c|c|c|c|}
\hline Parameters & Unit & Level 1 & Level 2 & Level 3 \\
\hline blank holder type (B) & - & 1 & 2 & 3 \\
\hline Rubber thickness (R) & $\mathrm{mm}$ & 2 & 4 & 6 \\
\hline Speed (D) & $\mathrm{mm} / \mathrm{min}$ & 2 & 5 & 10 \\
\hline
\end{tabular}

Table (4) methodology of Taguchi's L9 orthogonal array and response value

\begin{tabular}{|c|c|c|c|c|}
\hline \multicolumn{5}{|c|}{ Process Parameters } \\
\hline Exp. No. & blank holder type & $\begin{array}{c}\text { Rubber thickness } \\
\mathrm{mm}\end{array}$ & $\begin{array}{c}\text { Speed } \\
\mathrm{mm} / \mathrm{min}\end{array}$ & Max. Reduction \% \\
\hline $\mathbf{1}$ & 1 & 1 & 1 & 9.437 \\
\hline $\mathbf{2}$ & 1 & 2 & 2 & 10.188 \\
\hline $\mathbf{3}$ & 1 & 3 & 3 & 8.310 \\
\hline $\mathbf{4}$ & 2 & 1 & 2 & 10.516 \\
\hline $\mathbf{5}$ & 2 & 2 & 3 & 11.268 \\
\hline $\mathbf{6}$ & 2 & 3 & 1 & 9.859 \\
\hline $\mathbf{7}$ & 3 & 1 & 3 & 10.141 \\
\hline $\mathbf{8}$ & 3 & 2 & 1 & 9.155 \\
\hline $\mathbf{9}$ & 3 & 3 & 2 & 9.577 \\
\hline
\end{tabular}

Table (5) Experimental result of thickness reduction (\%) for each forming parts

\begin{tabular}{|c|c|c|c|c|c|c|c|c|c|c|}
\hline & \multicolumn{9}{|c|}{ Products Number } \\
\hline & & 1 & 2 & 3 & 4 & 5 & 6 & 7 & 8 & 9 \\
\hline \multirow{20}{*}{ 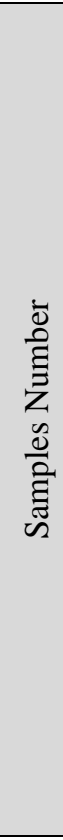 } & 1 & 0.469 & 0.657 & 0.610 & 0.657 & 0.516 & 0.657 & 0.516 & 0.516 & 0.188 \\
\hline & 2 & 1.315 & 1.878 & 1.737 & 1.643 & 2.160 & 1.925 & 1.596 & 1.972 & 1.831 \\
\hline & 3 & 3.192 & 2.629 & 3.192 & 2.441 & 3.333 & 3.146 & 3.146 & 2.864 & 2.817 \\
\hline & 4 & 4.272 & 3.005 & 4.131 & 2.864 & 4.366 & 4.319 & 4.413 & 4.131 & 4.131 \\
\hline & 5 & 5.681 & 3.991 & 5.681 & 3.568 & 6.479 & 5.446 & 6.150 & 5.305 & 5.211 \\
\hline & 6 & 6.854 & 5.164 & 6.197 & 5.117 & 8.451 & 7.700 & 8.779 & 6.479 & 6.901 \\
\hline & 7 & 7.653 & 7.042 & 7.042 & 6.901 & 9.343 & 8.873 & 9.437 & 8.498 & 7.934 \\
\hline & 8 & 8.826 & 9.437 & 8.075 & 7.606 & 10.235 & 8.122 & 10.094 & 7.042 & 8.732 \\
\hline & 9 & 7.371 & 10.188 & 5.681 & 9.014 & 10.845 & 7.887 & 9.437 & 5.869 & 9.390 \\
\hline & 10 & 9.343 & 8.404 & 7.418 & 10.329 & 11.268 & 8.404 & 8.732 & 4.789 & 7.934 \\
\hline & 11 & 9.437 & 6.854 & 7.934 & 9.155 & 9.812 & 9.014 & 7.089 & 4.225 & 6.150 \\
\hline & 12 & 8.498 & 8.451 & 7.653 & 10.516 & 8.779 & 9.859 & 8.357 & 6.479 & 7.981 \\
\hline & 13 & 7.512 & 9.108 & 5.962 & 9.437 & 8.357 & 8.685 & 9.249 & 7.606 & 8.592 \\
\hline & 14 & 9.531 & 9.671 & 6.854 & 8.122 & 7.230 & 7.559 & 10.141 & 9.155 & 9.577 \\
\hline & 15 & 9.765 & 9.765 & 8.310 & 7.324 & 5.446 & 6.854 & 8.685 & 6.901 & 8.169 \\
\hline & 16 & 5.869 & 7.089 & 6.244 & 6.244 & 4.085 & 5.775 & 7.042 & 5.070 & 6.009 \\
\hline & 17 & 4.836 & 5.352 & 4.460 & 4.225 & 3.099 & 5.211 & 5.023 & 4.178 & 4.225 \\
\hline & 18 & 3.615 & 4.131 & 2.582 & 3.286 & 2.394 & 3.850 & 3.850 & 3.474 & 3.192 \\
\hline & 19 & 1.174 & 2.160 & 1.784 & 1.878 & 1.643 & 1.831 & 2.864 & 2.347 & 1.878 \\
\hline & 20 & 0.376 & 1.033 & 0.610 & 0.610 & 1.127 & 1.127 & 0.188 & 0.094 & 0.845 \\
\hline
\end{tabular}


Table (6) Prediction of process parameters with respect to response value

\begin{tabular}{|l|l|l|l|l|}
\hline \multicolumn{5}{|c}{ Process Parameters } \\
\hline Exp. No. & blank holder type & $\begin{array}{c}\text { Rubber thickness } \\
\mathrm{mm}\end{array}$ & $\begin{array}{c}\text { Speed } \\
\mathrm{mm} / \mathrm{min}\end{array}$ & Thickness deviation \\
\hline $\mathbf{1}$ & 1 & 2 & 5 & 9.78 \\
\hline $\mathbf{2}$ & 1 & 2 & 10 & 9.163 \\
\hline $\mathbf{3}$ & 1 & 4 & 2 & 9.321 \\
\hline $\mathbf{4}$ & 1 & 4 & 10 & 9.658 \\
\hline $\mathbf{5}$ & 1 & 6 & 2 & 8.366 \\
\hline $\mathbf{6}$ & 1 & 6 & 5 & 8.995 \\
\hline $\mathbf{7}$ & 2 & 2 & 2 & 10.385 \\
\hline $\mathbf{8}$ & 2 & 2 & 10 & 10.722 \\
\hline $\mathbf{9}$ & 2 & 4 & 2 & 10.622 \\
\hline $\mathbf{1 0}$ & 2 & 4 & 5 & 11.253 \\
\hline $\mathbf{1 1}$ & 2 & 6 & 5 & 10.298 \\
\hline $\mathbf{1 2}$ & 2 & 6 & 10 & 10.003 \\
\hline $\mathbf{1 3}$ & 3 & 2 & 2 & 9.462 \\
\hline $\mathbf{1 4}$ & 3 & 2 & 5 & 10.093 \\
\hline $\mathbf{1 5}$ & 3 & 4 & 5 & 10.33 \\
\hline $\mathbf{1 6}$ & 3 & 4 & 10 & 10.035 \\
\hline $\mathbf{1 7}$ & 3 & 6 & 2 & 8.743 \\
\hline $\mathbf{1 8}$ & 3 & 6 & 10 & 9.08 \\
\hline
\end{tabular}

Table (7) Analysis of variance using ANOVA algorithm

\begin{tabular}{|c|c|c|c|c|c|}
\hline \multicolumn{6}{|c|}{ Analysis of Variance } \\
\hline source & Df & Adj ss & F-Value & P-Value & $F_{t}$ \\
\hline blank holder & 1 & 0.7248 & 13.54 & 0.002 & $\checkmark$ \\
\hline rubber & 1 & 2.341 & 43.72 & 0.0 & $\checkmark$ \\
\hline speed & 1 & 0.51 & 9.53 & 0.007 & $\checkmark$ \\
\hline \multicolumn{6}{|l|}{ Second order } \\
\hline blank $\mathrm{h}$ *blank $\mathrm{h}$ & 1 & 7.4193 & 138.58 & 0 & $\checkmark$ \\
\hline rubber*rubber & 1 & 2.1313 & 39.81 & 0 & $\checkmark$ \\
\hline speed*speed & 1 & 1.4994 & 28.01 & 0 & $\checkmark$ \\
\hline \multicolumn{6}{|l|}{ 2-Way Interaction } \\
\hline blank $\mathrm{h}$ *rubber & 1 & 0.0141 & 5.58 & 0.615 & $x$ \\
\hline blank h*speed & 1 & 0.2988 & 5.58 & 0.03 & $x$ \\
\hline rubber*speed & 1 & 0.0185 & 0.35 & 0.564 & $x$ \\
\hline Error & 17 & 3.5758 & & & \\
\hline Total & 26 & 15.5519 & & & \\
\hline
\end{tabular}




\section{REFERENCES}

A A Tolipov, A Elghawail, M Abosaf, S Shushing, D Pham and K Essa, Experimental research and numerical optimisation of multi-point sheet metal forming implementation using a solid elastic cushion system, Conference Paper, Department of Mechanical Engineering, School of Engineering, University of Birmingham,UK, July 2017.

Abdulkareem Jalil Kadhim, and Mostafa Imad Abbas, Three-Dimensional Experimental and Numerical Simulation of Sheet Metal Forming Process Based on Flexible Multipoint Die, International Journal of Mining, Metallurgy \& Mechanical Engineering (IJMMME) Volume 2, Issue 1, 2014.

Ming-Zhe Li, Zhong-Yi Cai, Chun-Guo Liu, Flexible manufacturing of sheet metal parts based on digitized-die, Robotics and Computer-Integrated Manufacturing 23 (2007) 107 115 .

Q. Zhang, Z.R. Wang, T.A. Dean, Multi-point sandwich forming of a spherical sector with tool-shape compensation, Journal of Materials Processing Technology 194 (2007) 74-80.

Tahseen Fadhel Abaas, Karem MohsenYounis and Khalida kadhim Mansor, Die Design of Flexible Multi-Point Forming Process, Al-Khwarizmi Engineering Journal, Vol. 14, No.2, June, P.P. 22- 29, 2018.

Yajie Liu, Mingzhe Li and Feifei Ju, Research on the process of flexible blank holder in multi-point forming for spherical surface parts, Springer, Int J Adv Manuf Technol, 89:2315-2017.

Zhong-Yi Cai, Ming-Zhe Li, Multi-point forming of three-dimensional sheet metal and the control of the forming process, International Journal of Pressure Vessels and Piping 79 (2002) 289-296.

Zhong-Yi Cai $\cdot$ Ming-Zhe Li - Xi-Di Chen, Digitized die forming system for sheet metal and springback minimizing technique, Int J Adv Manuf Technol (2006) 28: 1089-1096. 